\title{
光合产物传输方向对蓉城竹根际微生物过程的影响
}

\author{
邹 瓒 陈劲松 $^{2}$ 李 洋 ${ }^{1}$ 宋会兴 $^{1 *}$
}

${ }^{1}$ 四川农业大学风景园林学院, 成都 $611130{ }^{2}$ 四川师范大学生命科学学院, 成都 610101

摘 要 分株间光合产物的整合作用对克隆植物适应生存环境具有重要作用, 但有关光合产物传输方向对克隆植物根际土 壤微生物过程的影响尚不清楚。该研究以根状茎克隆植物蓉城竹(Phyllostachys bissetii)为研究对象, 通过剪除分株地上部分 控制光合产物传输方向(顶向传输和基向传输), 研究光合产物传输方向对蓉城竹分株根际土壤微生物过程的影响, 其中顶向 传输组是将远端分株地上部分剪除(保留地面以上 $20 \mathrm{~cm}$ ), 近端分株自然生长; 基向传输组则是将近端分株地上部分剪除(保 留地面以上 $20 \mathrm{~cm})$, 远端分株自然生长。两组实验中保持根状茎连接或切断处理。测定了地上部分被剪除分株根际土壤中碳 和氮有效性、微生物生物量参数以及氮转化相关土壤胞外酶活性等指标。结果表明: 光合产物顶向传输中, 根状茎保持连接 的远端分株根际土壤总有机碳 $(\mathrm{TOC})$ 、溶解性有机碳 $(\mathrm{DOC})$ 、溶解性有机氮 $(\mathrm{DON})$ 、铵态氮 $\left(\mathrm{NH}_{4}^{+}-\mathrm{N}\right)$ 、硝态氮 $\left(\mathrm{NO}_{3}^{-}-\mathrm{N}\right)$ 含量显 著高于切断的远端分株, N-乙酰基- $\beta$-D-氨基葡萄糖苷酶(NAGase)、多酚氧化酶(POXase)和腿酶(Urease)活性显著升高, 光合产 物的顶向传输对远端分株根际碳、氮有效性和根际微生物过程产生了显著性影响; 光合产物的基向传输中, 根状茎保持连接 的近端分株根际与切断分株相比具有更高的微生物生物量氮(MBN)含量、Urease、POXase活性, 较低的NAGase活性和 $\mathrm{NH}_{4}^{+}-\mathrm{N} 、 \mathrm{NO}_{3}^{-}-\mathrm{N}$ 含量, 但碳的有效性无显著性差异。蓉城竹分株间光合产物的非对称性传输对根际微生物过程的影响可能是 对动物取食或人为砍伐等干扰的有益权衡, 这有助于理解克隆植物对生存环境的种群适应机制。

关键词 光合产物传输方向; 根际土壤; 微生物过程; 土壤酶活性

邹瑽, 陈劲松, 李洋, 宋会兴 (2018). 光合产物传输方向对蓉城竹根际微生物过程的影响. 植物生态学报, 42, 863-872. DOI: 10.17521/cjpe.2018.0078

\section{Effects of transportation direction of photosynthate on soil microbial processes in the rhizosphere of Phyllostachys bissetii}

\author{
ZOU Zan ${ }^{1}$, CHEN Jin-Song ${ }^{2}$, LI Yang ${ }^{1}$, and SONG Hui-Xing ${ }^{1 *}$ \\ ${ }^{1}$ College of Landscape Architecture, Sichuan Agricultural University, Chengdu 611130, China; and ${ }^{2}$ College of Life Science, Sichuan Normal University, \\ Chengdu 610101, China
}

\begin{abstract}
Aims Clonal integration contributes greatly to the adaption of clonal plants to heterogeneous habitats. However, effects of transportation direction of photosynthate on microbial processes need to be further investigated in the rhizosphere. The purpose of this study is to determine the effects of directional differences in photosynthate transport on microbial processes in the rhizosphere of clonal plant Phyllostachys bissetii.
\end{abstract}

Methods By removing the aboveground parts of the ramets, acropetal treatment and basipetal treatment were applied in this study to control the transportation direction of photosynthate. In acropetal treatment, aboveground parts of distal ramets were cut off (with $20 \mathrm{~cm}$ above ground kept), and proximal ramets were left intact. While in basipetal treatment, aboveground parts of proximal ramets were cut off (with $20 \mathrm{~cm}$ above ground kept), and distal ramets were left intact. Rhizomes between the two ramets were either connected or severed. Carbon (C) and nitrogen $(\mathrm{N})$ availabilities, and enzyme activities in the rhizosphere soils were measured.

Important findings In acropetal treatment, total organic carbon (TOC), dissolved organic carbon (DOC), dissolved organic nitrogen (DON) and soil inorganic nitrogen $\left(\mathrm{NH}_{4}^{+}-\mathrm{N}\right.$ and $\left.\mathrm{NO}_{3}^{-}-\mathrm{N}\right)$ content in the rhizosphere soil of distal ramets with connected rhizomes were significantly higher than those with severed rhizome. The activities of urease, polyphenol oxidase (POXase), N-acetyl- $\beta$-D-Glucosaminidase (NAGase) were significantly enhanced. Further, clonal integration had a significant effect on $\mathrm{C}$ and $\mathrm{N}$ availability, and microbial processes in the rhizosphere soil of neighbouring ramets. In basipetal treatment, clonal integration did not show a significant effect 
on $\mathrm{C}$ availability in the rhizosphere soil of proximal ramets, but microbial processes along with soil enzyme activities were altered accordingly. Effects of transportation direction of photosynthate on microbial processes in the rhizosphere of $P$. bissetii provides insights into the adaptation mechanisms of clonal plant populations.

Key words transportation direction of photosynthate; rhizosphere soil; microbial process; soil enzymes activities

Zou Z, Chen JS, Li Y, Song HX (2018). Effects of transportation direction of photosynthate on soil microbial processes in the rhizosphere of Phyllostachys bissetii. Chinese Journal of Plant Ecology, 42, 863-872. DOI: 10.17521/cjpe.2018.0078

通过维管组织的传输, 植物实现光合产物在各 器官中资源分配的权衡(平晓燕等, 2010); 根系通过 根际沉积作用为土壤环境提供可利用碳源(Kuzyakov, 2002; Jones et al., 2009; Rajaniemi \& Allison, 2009)，这些易溶性碳源促进了土壤微生物生长代 谢过程, 调控土壤有机质的矿化、降解和转移、氮 $(\mathrm{N})$ 循环等过程(Schimel \& Weintraub, 2003; Trudell et al., 2004; Lei et al., 2014)。树木环割实验结果证实, 阻断Fagus sylvatica地上部分碳同化产物向根系的 传输, 会削弱根际土壤碳(C)的有效性, 显著影响根 际微生物过程(Koranda et al., 2011)。

相比非克隆植物, 克隆植物不仅存在分株内地 上部分与地下部分资源分配的权衡关系, 分株之间 也存在光合产物、水分和矿质养分的整合(张称意等, 2001; Li et al., 2002; 王昱生等, 2004; 彭一可等, 2013; 胡俊靖等, 2015)。对欧活血丹(Glechoma hederacea)、羊柴(Hedysarum laeve)、Carex bigelowii 资源传输格局的同位素示踪研究表明, 光合产物在 连接分株间均存在顶向传输和基向传输(Jónsdóttir \& Callaghan, 1990; Price \& Hutchings, 1992; 张称意 等, 2001); 分株间主要的资源传输格局是顶向传输, 即年长分株向年幼分株的物质传输比从年幼分株向 年长分株的物质传输要普遍得多(Pitelka \& Ashmmun, 1985; Marshall, 1990; Stuefer, 1996; 王长爱等, 2006; 张文军, 2014), 这在 $\mathrm{N}$ 资源的整合中尤为明 显(Alpert et al., 2002)。

克隆植物分株间资源传输的方向性差异对邻体 分株根际微生物过程的影响尚不清晰, 现有研究结 果也不尽相同。Lei等(2014)研究发现, 分株之间的 克隆整合作用使得遮阴远端分株根际 $\mathrm{C} 、 \mathrm{~N}$ 的有效性 显著增加, 微生物群落结构也发生显著性变化, 表 现出较强的根际过程。在蓉城竹(Phyllostachys bissetii)中, 尽管克隆整合显著增加了遮阴蓉城竹分株 根际 $\mathrm{C}$ 的有效性, 但根状茎切断处理并没有对遮阴 分株根际细菌的群落结构产生显著性影响(薛阁等, 2018)。推测这可能与植物种类不同有关, 更与资源
类型(如 $\mathrm{C}$ 和 $\mathrm{N}$ )不同而表现出的不同传输方向密切 关联(Alpert et al., 2002)。

竹林是中国森林植被的重要组成部分。竹类植 物是以木本为主的克隆植物, 其克隆生长特征对异 质性生境具有很强的适应能力(施建敏等, 2014)。这 一方面有利于高异质性生境的植被保持和生物多样 性保育(邱尔发等, 2001; 李睿等, 2003); 另一方面 竹林入侵其他群落所造成的群落结构破坏、生物多 样性降低、生态功能下降等负面影响日益受到关注 (白尚斌等, 2013; 刘骏等, 2013; 杨清培, 2017)。

因此, 我们提出如下假设: 克隆植物分株间光 合产物的传输格局使得远端分株(年幼分株)获得更 多的光合碳分配，根际可利用碳资源的增加影响根 际微生物过程; 而近端分株(年长分株)获得较少或 不能获得光合碳分配, 克隆整合不会对近端分株根 际微生物过程产生显著影响。本研究以单轴散生型 克隆植物——蓉城竹为对象, 探讨克隆分株间光合 产物传输对邻体分株根际微生物过程的影响, 这对 于理解竹类植物的种群适应机制具有重要的理论意 义。

\section{1 材料和方法}

\section{1 研究材料}

蓉城竹别名白夹竹, 属禾本科刚竹属(Phyllostachys), 株高3-6 m, 基径约 $2 \mathrm{~cm}$ 。蓉城竹为单轴散 生竹, 通过竹鞭(根状茎)进行克隆生长, 鞭梢生长 期6-11月，11月后停止生长，次年3-4月发笋，5月出 笋成竹(曾林等, 1998)。蓉城竹竹竿可用于造纸、编 䉝, 笋可食用, 具有重要的经济价值, 同时也是大 熊猫的主食竹之一(宋会兴等, 2011)。

\section{2 实验设计}

实验样地位于四川省成都市邛崃市南宝山镇 $\left(103.19^{\circ} \mathrm{E}, 30.45^{\circ} \mathrm{N}\right)$, 海拔 $1217 \mathrm{~m}$, 年平均气温 $16.3{ }^{\circ} \mathrm{C}$ ，年日照时间 $1107.9 \mathrm{~h}$ ，年降水量 $1117.3 \mathrm{~mm}$ 。2015年11月, 选取当年生、长势一致的 蓉城竹分株对，控制分株间距在 $(30 \pm 5) \mathrm{cm}(n=12)$ 
范围内, 依据竹鞭走向分别标记分株对的近端分株 和远端分株。切断分株对外围竹鞭, 用双层加厚塑 料膜包裹蓉城竹根部土块 $($ 大小为 $0.5 \mathrm{~m} \times 0.5 \mathrm{~m})$ 与 周围环境隔离, 以排除外界土壤环境对实验分株对 的影响。实验分顶向传输(A)和基向传输(B)两组: 顶 向传输组中, 将远端分株地上部分剪除(保留地面 以上 $20 \mathrm{~cm}$ ), 近端分株自然生长; 基向传输组中, 将近端分株地上部分剪除(保留地面以上 $20 \mathrm{~cm}$ ), 远 端分株自然生长。两组实验中保持根状茎连接或切 断处理, 每处理3个重复, 共12个分株对(图1)。

\section{3 土壤样品收集及相关指标测定}

2016年11月，按照Riley和Barber (1970)的“抖落 法”, 对地上部分剪除的分株根际进行土壤取样。具 体操作为: 将没有黏附在根上的非根际土壤抖落, 紧密黏附在根上、距离根系表面1-3 mm的土壤作为 根际土壤, 用无菌毛刷轻轻刷下, 手工捡出动植物 残体、砾石等, 过篎 $(<2 \mathrm{~mm})$ 后保存于干燥灭菌的自 封袋中(孙悦等, 2014; Guo et al., 2016), 用于相关指 标的测定。不能及时测量的土壤样品置于 $-20{ }^{\circ} \mathrm{C}$ 冰 箱备用。

\subsection{1 根际土壤碳氮有效性}

土壤总有机碳(TOC)和总氮(TN)含量采用元素 分析仪(vario MACRO cube, Elementar, Langenselbold, Germany)测定; 溶解性有机碳(DOC) 和溶

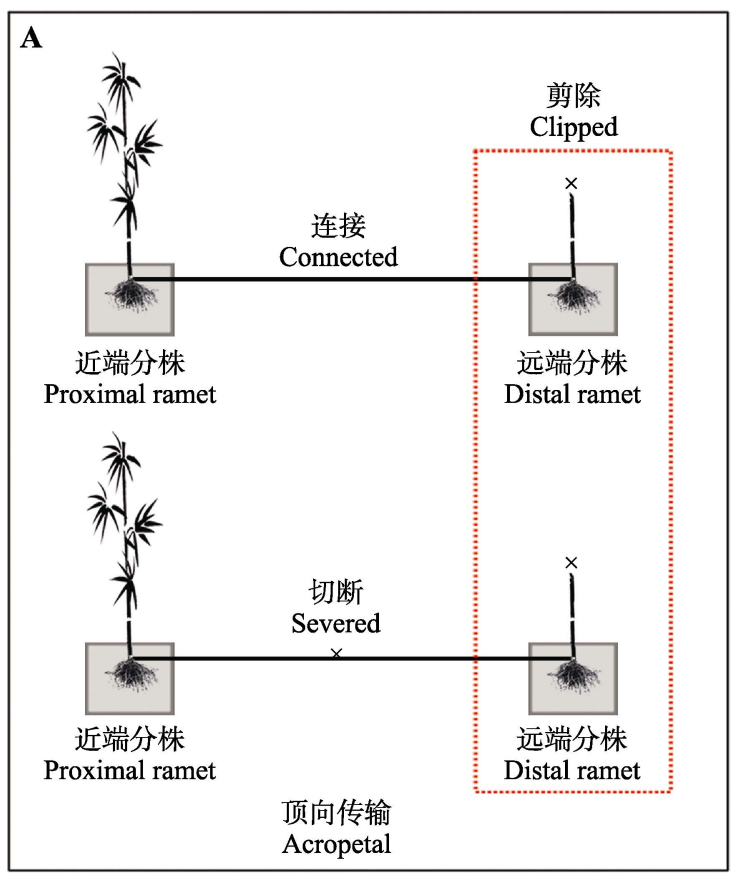

图1 实验设计图。

Fig. 1 Schematic diagram of experiment design.
解性有机氮(DON)用 $0.5 \mathrm{~mol} \cdot \mathrm{L}^{-1} \quad \mathrm{~K}_{2} \mathrm{SO}_{4}$ 溶液浸提, 于TOC/TN分析仪(TOC-L analyzer, Shimadzu, Kyoto, Japan)中测定其含量; 土壤微生物生物量碳(MBC) 和生物量氮( $\mathrm{MBN})$ 采用氯仿熏蒸提取法(CFAP)进 行提取(Witt et al., 2000; Setia et al., 2012), 于 TOC/TN分析仪中测定其熏蒸处理和未熏蒸处理后 的DOC、DON含量, 通过Vance等(1987)和 Wu等 (1990)提出的公式计算土壤微生物生物量碳(氮)含 量:

$$
\operatorname{MBC}(N)=E_{\mathrm{B}} / 0.45
$$

其中 $E_{\mathrm{B}}$ 是进行氯仿熏蒸处理与未熏蒸处理的浸提 液DOC、DON含量差值, 0.45 为转换系数。

土壤无机氮即铵态氮 $\left(\mathrm{NH}_{4}{ }^{+}-\mathrm{N}\right)$ 和硝态氮 $\left(\mathrm{NO}_{3}^{-}-\mathrm{N}\right)$, 用 $2 \mathrm{~mol} \cdot \mathrm{L}^{-1} \mathrm{KCl}$ 溶液浸提后分别采用靛 酚蓝比色法和双波长比色法测定含量(Crepin \& Johnson, 1993); 同时将等量土样于 $40{ }^{\circ} \mathrm{C}$ 恒温箱中 培养7昼夜, 测定 $\mathrm{NH}_{4}^{+}-\mathrm{N}$ 和 $\mathrm{NO}_{3}^{-}-\mathrm{N}$ 含量, 根据以下公 式(Zhou et al., 2011)计算土壤样品的净矿化速率 $\left(N_{\text {min }}\right)$ 和硝化速率 $\left(N_{\text {nitri }}\right)$ :

$$
\begin{aligned}
& N_{\text {min }}=\frac{\left(\mathrm{NH}_{4}^{+}+\mathrm{NO}_{3}^{-}\right)_{\text {培养后 }}-\left(\mathrm{NH}_{4}^{+}+\mathrm{NO}_{3}^{-}\right)_{\text {培养前 }}}{\text { 培养时间 } t} \\
& N_{\text {nitri }}=\frac{\left(\mathrm{NO}_{3}^{-}\right)_{\text {培养后 }}-\left(\mathrm{NO}_{3}^{-}\right)_{\text {培养前 }}}{\text { 培养时间 } t}
\end{aligned}
$$

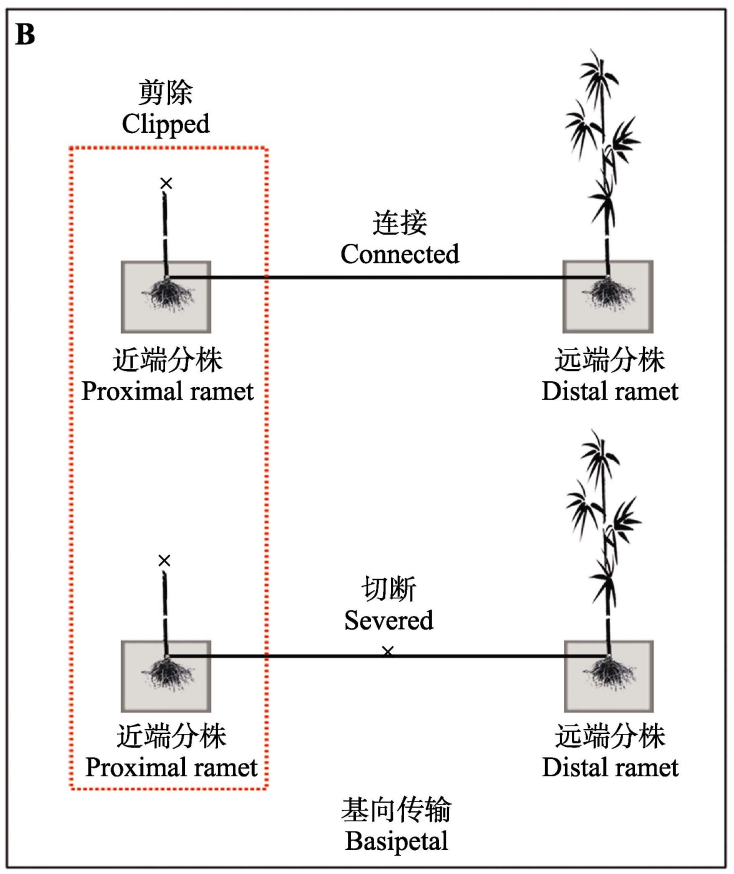




\subsection{2 土壤酶活性}

$\mathrm{N}$-乙酰基- $\beta-\mathrm{D}$-氨基葡萄糖苷酶(NAGase)、多酚 氧化酶(POXase)和嫝酶(Urease)均为在根际土壤C、 $\mathrm{N}$ 转化过程中起重要作用的土壤酶, 其中NAGase参 与壳多糖水解, 是决定土壤有机碳来源的重要因子 (Smucker \& Kim, 1987); POXase则对土壤腐殖质碳 的形成有重要作用(关松荫, 1986); 而Urease参与土 壤中有机氮向有效氮的转化过程, 一定程度上反映 土壤无机氮的供应能力(Gianfreda et al., 2005)。本研 究中NAGase采用Parham和Deng (2000)的方法, 以 对硝基苯酚-N-乙酰基- $\beta-D$ - 氨基葡萄糖苷 $(\rho N P-$ $\mathrm{NAG})$ 为底物进行测定, 活性用 $\mu \mathrm{g} \cdot \mathrm{g}^{-1} \mathrm{soil} \cdot \mathrm{h}^{-1}$ 表示; Urease采用Kandeler和Gerber (1988)的方法, 以尿素 作为底物进行测定, 活性用 $\mu \mathrm{g} \cdot \mathrm{g}^{-1} \mathrm{soil} \cdot \mathrm{h}^{-1}$ 表示; POXase采用Perucci等(2000)等的方法, 以邻苯二酚 为底物进行测定, 活性用 $\mu \mathrm{mol} \cdot \mathrm{g}^{-1} \cdot \mathrm{min}^{-1}$ 表示。

\section{4 数据分析}

采用IBM SPSS Statistics 19软件对数据进行正 态检验, 以 $\mathrm{S}-\mathrm{W}$ 检验结果为准, $p$ 值设置为 0.05 ; 对 数据进行方差齐性检验(Levene's test), 检验的显著 性概率临界值为 0.05 ; 通过单因素方差分析方法分 析根状茎连接与否对根际土壤 $\mathrm{C} 、 \mathrm{~N}$ 有效性、酶活性、 矿化速率及硝化速率的影响。采用OriginPro 8软件 完成绘图。

\section{2 结果}

\section{1 根际土壤C、N有效性}

光合产物顶向传输中, 根状茎连接的远端分株
根际的TOC、DOC、DON、 $\mathrm{NH}_{4}^{+}-\mathrm{N}$ 和 $\mathrm{NO}_{3}^{-}-\mathrm{N}$ 含量显 著高于根状茎切断的远端分株, 但 $\mathrm{TN}$ 含量差异不 显著; 光合产物基向传输中, 根状茎连接的近端分 株根际DON、 $\mathrm{NH}_{4}^{+}-\mathrm{N}$ 和 $\mathrm{NO}_{3}^{-}-\mathrm{N}$ 的含量显著低于根状 茎切断分株, 而根状茎切断与否对 TOC、TN和DOC 含量无显著影响(表1)。

\section{2 根际土壤微生物生物量特征}

光合产物顶向传输中, 根状茎保持连接的远端 分株根际土壤 $\mathrm{MBC}$ 含量显著高于根状茎切断的分 株, 但切断根状茎并没有显著影响根际土壤 $\mathrm{MBN}$ 含量; 光合产物基向传输中, 切断根状茎没有显著 影响根际土壤 $\mathrm{MBC}$ 含量, 却显著改变了根际土壤 $\mathrm{MBN}$ 含量, 使得根状茎保持连接的近端分株根际 土壤 $\mathrm{MBN}$ 含量显著高于根状茎切断的近端分株根 际(表1)。

$\mathrm{MBC} / \mathrm{MBN}$ 值在两个实验中也表现出了不同的 变化趋势，在光合产物顶向传输中，根状茎保持连 接的远端分株根际 $\mathrm{MBC} / \mathrm{MBN}$ 值为 8.282 ，显著高于 切断根状茎的远端分株根际; 在光合产物基向传输 中恰好相反, 表现为根状茎保持连接的近端分株根 际 $\mathrm{MBC} / \mathrm{MBN}$ 值显著低于切断根状茎的近端分株根 际(表1)。

\section{3 根际土壤酶活性}

光合产物顶向传输中, 根状茎保持连接的远端 分株根际NAGase、POXase和Urease活性均显著高于 根状茎切断的远端分株根际; 但在光合产物基向传 输实验中 3 个酶的变化趋势并不一致：其中Urease 与POXase活性变化与顶向传输组一致，表现为根

表1 光合产物传输方向对蓉城竹根际土壤性质的影响(平均值土标准偏差)

Table 1 Effects of transportation direction of photosynthate on soil properties in the rhizosphere of Phyllostachys bissetii ( $\operatorname{mean} \pm S D)$

\begin{tabular}{|c|c|c|c|c|}
\hline \multirow{2}{*}{$\begin{array}{l}\text { 土壤性质 } \\
\text { Soil properties }\end{array}$} & \multicolumn{2}{|c|}{ 顶向传输组 Acropetal treatment } & \multicolumn{2}{|c|}{ 基向传输组 Basitpetal treatment } \\
\hline & 连接 Connected & 切断 Severed & 连接 Connected & 切断 Severed \\
\hline TOC $\left(g \cdot \mathrm{kg}^{-1}\right)$ & $8.859 \pm 0.139$ & $8.221 \pm 0.048^{* *}$ & $8.513 \pm 0.108$ & $8.697 \pm 0.170$ \\
\hline $\mathrm{TN}\left(\mathrm{g} \cdot \mathrm{kg}^{-1}\right)$ & $1.707 \pm 0.149$ & $1.560 \pm 0.172$ & $1.569 \pm 0.073$ & $1.617 \pm 0.088$ \\
\hline $\operatorname{DOC}\left(\mathrm{mg} \cdot \mathrm{kg}^{-1}\right)$ & $62.683 \pm 0.293$ & $58.23 \pm 0.621^{* * *}$ & $56.017 \pm 0.180$ & $56.163 \pm 0.295$ \\
\hline $\operatorname{DON}\left(\mathrm{mg} \cdot \mathrm{kg}^{-1}\right)$ & $7.99 \pm 0.105$ & $6.674 \pm 0.042^{* * *}$ & $7.126 \pm 0.079$ & $7.422 \pm 0.041^{* *}$ \\
\hline $\operatorname{MBC}\left(\mathrm{mg} \cdot \mathrm{kg}^{-1}\right)$ & $20.052 \pm 1.725$ & $14.621 \pm 0.719^{* *}$ & $21.467 \pm 1.156$ & $19.238 \pm 1.186$ \\
\hline $\operatorname{MBN}\left(\mathrm{mg} \cdot \mathrm{kg}^{-1}\right)$ & $2.456 \pm 0.414$ & $3.084 \pm 0.151$ & $2.522 \pm 0.244$ & $1.599 \pm 0.138^{* *}$ \\
\hline $\mathrm{MBC} / \mathrm{MBN}$ & $8.282 \pm 1.225$ & $4.750 \pm 0.371^{* *}$ & $8.551 \pm 0.716$ & $12.083 \pm 1.148^{*}$ \\
\hline $\mathrm{NH}_{4}^{+}-\mathrm{N}\left(\mathrm{mg} \cdot \mathrm{kg}^{-1}\right)$ & $7.206 \pm 0.234$ & $5.557 \pm 0.368^{* *}$ & $5.531 \pm 0.127$ & $6.957 \pm 0.181^{* * *}$ \\
\hline $\mathrm{NO}_{3}^{-}-\mathrm{N}\left(\mathrm{mg} \cdot \mathrm{kg}^{-1}\right)$ & $1.908 \pm 0.120$ & $1.224 \pm 0.203^{* *}$ & $1.467 \pm 0.175$ & $2.304 \pm 0.441^{*}$ \\
\hline
\end{tabular}

根状茎连接与切断分株间显著性检验表示为: ***, $p<0.001 ; * *, p<0.01 ; *, p<0.05$ 。 DOC, 溶解性有机碳; DON, 溶解性有机氮; MBC, 微生物生物量 碳; MBN，微生物生物量氮; TN，总氮; TOC，总有机碳。

The significant differences between rhizome connected ramets and rhizome severed ramets were indicated by $* * *(p<0.001), * *(p<0.01)$, and $*(p<0.05)$. DOC, dissolved organic carbon; DON, dissolved organic nitrogen; MBC, microbial biomass carbon; MBN, microbial biomass nitrogen; TN, total nitrogen; TOC, total organic carbon.

www.plant-ecology.com 
状茎连接近端分株显著高于根状茎切断的近端分株; NAGase活性变化与顶向传输实验相反, 表现为根 状茎连接近端分株显著低于根状茎切断的近端分株 (图2)。

\section{4 根际土壤 $\mathrm{N}$ 矿化、硝化速率}

光合产物顶向传输中, 根状茎切断并没有对远 端分株根际土壤 $N_{\min }$ 与 $N_{\text {nitri }}$ 产生显著性影响; 在光 合产物基向传输中, 根状茎保持连接与否没有对近 端分株根际 $N_{\min }$ 产生显著影响, 但显著影响了其 $N_{\text {nitri }}$, 根状茎保持连接的近端分株根际 $N_{\text {nitri 显著高 }}$ 于根状茎切断分株(图3)。

\section{3 讨论}

3.1 光合产物传输对蓉城竹根际 $\mathrm{C} 、 \mathrm{~N}$ 有效性的 影响

根际沉积作用是植物根系为土壤环境提供可利 用碳源的重要方式(Kuzyakov, 2002; Jones et al., 2009)。在蓉城竹中, 根状茎保持连接的远端分株根
际TOC、DOC含量均显著高于根状茎切断的远端分 株，这与遮阴活血丹(Glechoma longituba)远端分株 具有较高的DOC含量是一致的(Lei et al., 2014), 暗 示了地上部分被剪除的远端分株根际, 获得了近端 分株光合产物的支持。而根际氮肥有效性的增加能 显著增加绿竹(Dendrocalamopsis oldhami)的竹笋产 量(曾爱平等, 2007), 意味着蓉城竹远端分株地上部 分被剪除后出笋量可能增加。

光合产物基向传输中, 根状茎保持切断与否并 没有显著影响近端分株根际TOC、DOC含量, 这一 方面是由于植物地上部分去除会引起植物的补偿效 应, 即将根系积累的碳水化合物重新输送到地上部 分，进而影响根系的沉积作用(Giese et al., 2013); 另一方面, 光合产物的传输主要是顶向传输, 而基 向传输中传输的量较少, 从而影响了近端分株根际 C 有效性(D’Hertefeldt \& Jónsdóttir, 1999)。

植株根际 $\mathrm{C}$ 有效性的增加, 促进了土壤微生物 生长代谢过程(赵劲松等, 2003), 加快了微生物调控
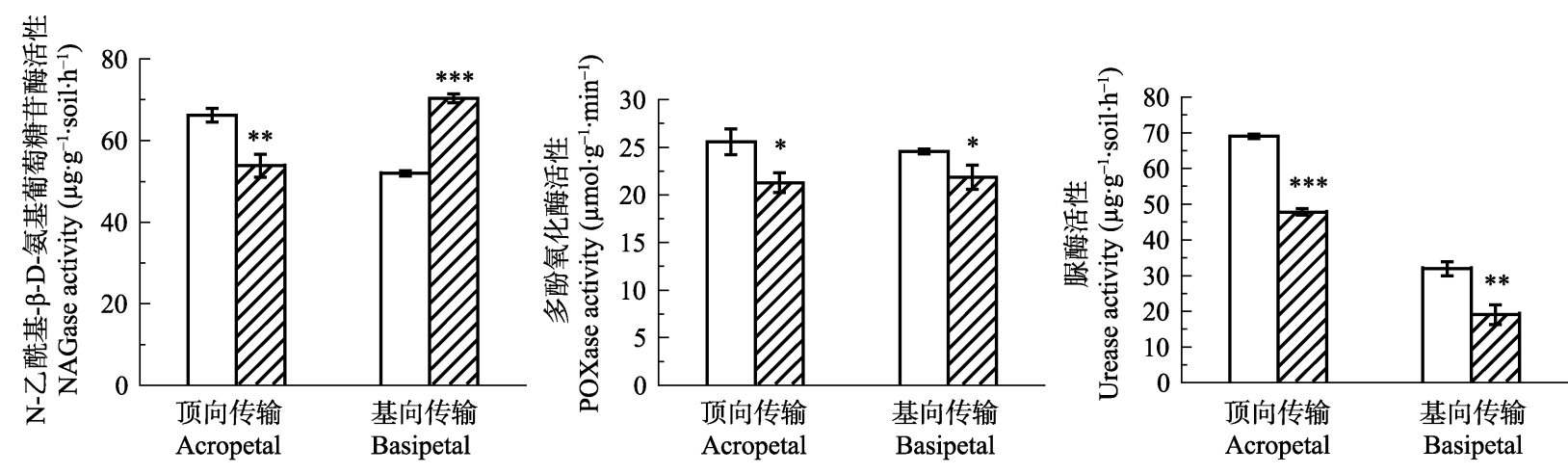

连接 Connected ZZ切断 Severed

图2 光合产物传输对蓉城竹根际土壤酶活性的影响(平均值土标准偏差). ${ }^{* *}, p<0.001 ; * *, p<0.01 ; *, p<0.05$ 。

Fig. 2 Effects of transportation direction of photosynthate on soil enzyme activities in the rhizosphere of Phyllostachys bissetii (means $\pm S D$ ). NAGase, N-acetyl- $\beta$-D-glucosaminidase; POXase, phenol oxidase. ${ }^{* * *}, p<0.001 ; * *, p<0.01 ; *, p<0.05$.
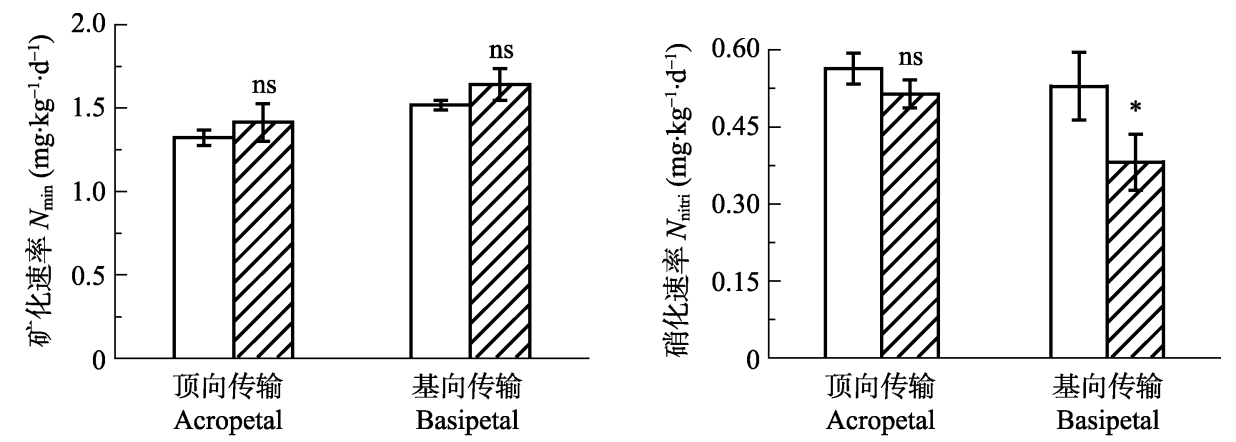

图3 光合产物传输对蓉城竹根际土壤氮素矿化速率 $\left(N_{\min }\right)$ 和硝化速率 $\left(N_{\text {nitri }}\right)$ 的影响(平均值土标准偏差)。***, $p<0.001 ; * *, p<$ $0.01 ; *, p<0.05$ 。

Fig. 3 Effects of transportation direction of photosynthate on soil $\mathrm{N}$ mineralization $\operatorname{rate}\left(N_{\min }\right)$ and nitrification $\operatorname{rate}\left(N_{\text {nitri }}\right)$ in the rhizosphere of Phyllostachys bissetii(means $\pm S D$ ). ${ }^{* * *}, p<0.001 ;{ }^{* *}, p<0.01 ;{ }^{*}, p<0.05$. 
的 $\mathrm{N}$ 转化过程, 使得根状茎保持连接的蓉城竹远端 分株根际具有较高的 $\mathrm{N}$ 有效性(表1), 这与对活血丹 的研究结果是一致的(Lei et al., 2014)。而在光合产 物基向传输中, 根状茎保持连接的近端分株根际 $\mathrm{NH}_{4}^{+}-\mathrm{N}$ 和 $\mathrm{NO}_{3}^{-}-\mathrm{N}$ 浓度显著低于切断分株。同位素示 踪实验发现，年龄较大的无叶分株可以保持较高的 根系吸收活力, 其功能特化为吸收地下资源并传递 给年龄较小的具叶分株, 维持年幼分株的顶端优势 和生长(Jónsdóttir \& Callaghan, 1990)。此外, 光合产 物基向传输中根状茎连接近端分株根系分泌的有机 碳促进了根际土壤微生物的生长, 表现出了较高的 微生物生物量, 但其对根际 $\mathrm{N}$ 的竞争能力远远强于 微生物对营养的摄取, 这种植物和微生物对 $\mathrm{N}$ 的竞 争策略同时也是生态系统 $\mathrm{N}$ 循环的重要环节 (Schimel \& Bennett, 2004; 章晴, 2016)。因此, 根际 土壤N有效性同时受到植物根系吸收、土壤微生物 摄取以及根际土壤N矿化硝化作用等多方面因素的 影响, 且根系吸收的能力与根系的生理年龄、根量 等有关(钦绳武和刘芷宇, 1984; 章晴, 2016)。同时, 由于光合产物在不同方向上传输量的差异, 使得地 上部分剪除后蓉城竹近端、远端分株根际 $\mathrm{N}$ 有效性 发生了迥异变化。

\section{2 光合产物传输对蓉城竹根际土壤酶活性的影响}

根际区域土壤酶活性主要受到根系分泌物、根 系调落物及土壤微生物群落结构组成和土壤微生物 活性等因素的影响(Toberman et al., 2011)。在远端分 株根际, 根状茎保持连接的植株土壤酶活性显著高 于根状茎断开植株。这在紫竹 (Phyllostachys nigra)(张云和陈劲松, 2017)、活血丹(Lei et al., 2014) 等中也有发现, 这与根状茎保持连接的远端分株根 际通过整合作用获得了更多的光合碳资源, 改变了 土壤微生物群落结构和活性有关(Rajaniemi \& Allison, 2009)。树木环割(Koranda et al., 2011)以及牧草 刏割(章家恩等, 2005)后土壤酶活性的变化也间接 证明了我们的研究结果。

在光合产物基向传输中, 根状茎连接近端分株 根际土壤Urease和POXase活性依旧高于根状茎切 断的近端分株, 而NAGase活性恰好相反, 根状茎切 断近端分株显著高于根状茎保持连接近端分株。有 关植物根系活力与Urease、POXase活性正相关的研 究结果在烟草(Nicotiana tabacum)(李艳平等, 2016)、 番茄(Lycopersicon esculentum)(吴瑕等, 2015)中均有
报道。因此我们推测土壤Urease和POXase活性变化 可能与根状茎连接分株较切断分株具有更高的根系 活力有关; 而根际 NAGase 活性与土壤真菌 Glomeromycota (球囊菌门)丰度显著负相关(李丽华, 2016)。球囊菌是构成陆生植物从枝菌根的主体, 需 从宿主植物中获取碳及能量才能生存。由此推测, 尽管在蓉城竹中光合产物基向传输的量不足以引起 根际TOC、DOC浓度的显著变化，但依旧能够维持 共生的从枝菌根菌的生存, 从而影响着根际 NAGase活性。

\section{3 光合产物传输对蓉城竹根际土壤微生物量特 征的影响}

土壤微生物参与了土壤有机质的转化过程, 在 植物养分有效性和腐殖质形成过程中发挥着重要作 用(Bardgett et al., 2005)。通常采用 $\mathrm{MBC} / \mathrm{MBN}$ 来评 价土壤微生物种群结构(Paul \& Clark, 1989)。有研究 表明, 少量的根系分泌物会影响土壤微生物活性, 而在根系分泌物量较大时, 细菌与真菌的相对多度 发生改变, 影响土壤微生物群落结构(de Graaff et al., 2010)。在根状茎保持连接的蓉城竹远端分株根 际, $\mathrm{MBC}$ 含量显著高于切断分株, 连接和切断分株 $\mathrm{MBC} / \mathrm{MBN}$ 差异显著, 是蓉城竹生理整合作用下远 端分株根际沉积作用的结果。光合产物顶向传输实 验中根状茎切断与否并没有对 $\mathrm{MBN}$ 含量产生显著 影响。黑杨(Populus nigra)、水杉(Metasequoia glyptostroboides)根际的添加实验表明, $\mathrm{C} / \mathrm{N}$ 较高的低分子 量有机碳对根际土壤MBN含量没有显著影响(章晴, 2016)。

在光合产物基向传输中, $\mathrm{MBC} / \mathrm{MBN}$ 在保持连 接的蓉城竹分株根际与根状茎切断的分株根际存在 显著差异, 预示着根状茎连接与否对近端分株根际 土壤微生物群落组成产生了显著影响。这可能是根 状茎切断后与近端分株根系共生的从枝菌根真菌生 长受限及(或)腐生真菌增多的原因(Koranda et al., 2011)。

\section{4 光合产物传输对蓉城竹根际土壤N矿化、硝化 速率特征的影响}

$\mathrm{N}$ 矿化是土壤氮循环一个最重要的过程, 微生 物是土壤 $\mathrm{N}$ 矿化过程重要的参与者, 土壤有机质与 根际沉积物可促进微生物的矿化作用(Rajaniemi \& Allison, 2009)。通过向土壤中添加易分解有机碳, 发现根系分泌物的增加会加速或抑制 $\mathrm{N}$ 矿化过程, 
而表现为正激发效应(Hamer \& Marschner, 2005; Kuzyakov et al., 2007)或负激发效应(Kuzyakov \& Bol, 2006; Blagodatskaya et al., 2007)。de Graaff等 (2010)认为这是根系分泌物量的高低造成的结果。 在我们的研究中, 无论在光合产物顶向传输还是基 向传输实验中, $N_{\min }$ 都没有发生显著性变化, $N_{\text {nitri }}$ 仅 仅是在基向传输实验中连接分株显著高于根状茎断 开分株。由于实验并没有对根系分泌物的数量进行 研究, 出现这一结果的机制并不清楚。此外, 测定的 土壤N矿化、硝化速率属于瞬时变化, 不同于根际 C、N有效性及土壤酶活性等具有累积效应(Zhou et

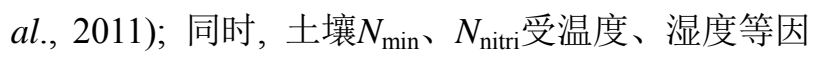
子的影响(Mcmurtrie et al., 2001; Zaman \& Chang, 2004), 季节性变化明显, 对土壤 $N_{\text {min }} 、 N_{\text {nitri动态的研 }}$ 究有助于揭示这一研究结果的详细机制。

总之, 控制性实验造成的光合产物传输方向差 异使得蓉城竹近端和远端分株根际 $\mathrm{C}$ 有效性产生不 同变化, 进而对根际土壤酶活性等微生物过程产生 了不同的影响，意味着克隆植物分株间光合产物传 输的非对称性。光合产物顶向传输的优势促进了远 端分株根际 $\mathrm{N}$ 有效性, 可能有利于受动物取食或人 为砍伐等干扰影响的蓉城竹分株的再生长(如新生 笋的萌发和生长)(周世强等, 2009; 魏宇航, 2013)。 而根状茎保持连接的近端分株地上部分剪除后地下 部分功能特化, 保持较高的根系活力(Jónsdóttir \& Callaghan, 1990), 但其根际较低的 $\mathrm{N}$ 有效性似乎暗 示了其根际存在一定的营养转移(可能供给幼嫩分 株或土壤微生物)。因此, 蓉城竹分株地上部分剪除 形成的分株间光合产物非对称性传输, 影响了根际 微生物过程, 这可能是蓉城竹对动物取食或人为砍 伐等干扰的有益权衡，是对自身克隆片段的“取舍”, 这有助于克隆植物对生存环境的适应调节。

致谢 长江上游生态安全协同创新中心开放基金项 目资助, 特此致谢!

\section{参考文献}

Alpert P, Holzapfel C, Benson JM (2002). Hormonal modification of resource sharing in the clonal plant Fragaria chiloensis. Functional Ecology, 16, 191-197.

Bai SB, Zhou GM, Wang YX, Liang QQ, Chen J, Cheng YY, Shen R (2013). Plant species diversity and dynamics in forests invaded by Moso bamboo (Phyllostachys edulis) in Tianmu Mountain Nature Reserve. Biodiversity Science,
21，288-295. [白尚斌, 周国模, 王懿祥, 梁倩倩, 陈娟, 程艳艳, 沈荵 (2013). 天目山保护区森林群落植物多样 性对毛竹入侵的响应及动态变化. 生物多样性, 21, 288-295.]

Bardgett RD, Yeates GW, Anderson JM (2005). Patterns and determinants of soil biological diversity. In: Bardgett RD, Usher MB, Hopkins DW eds. Biological Diversity and Function in Soils. Cambridge University Press, Cambridge, UK. 100-118.

Blagodatskaya EV, Blagodatsky SA, Anderson TH, Kuzyakov Y (2007). Priming effects in Chernozem induced by glucose and $\mathrm{N}$ in relation to microbial growth strategies. Applied Soil Ecology, 37, 95-105.

Crepin J, Johnson LR (1993). Soil sampling and methods of analysis. Journal of Environmental Quality, 38, 15-24.

D’Hertefeldt T, Jónsdóttir I (1999). Extensive physiological integration in intact clonal systems of Carex arenaria. Journal of Ecology, 87, 258-264.

de Graaff M, Classen AT, Castro HF, Schadt CW (2010). Labile soil carbon inputs mediate the soil microbial community composition and plant residue decomposition rates. New Phytologist, 188, 1055-1064.

Gianfreda L, Rao MA, Piotrowska A, Palumbo G, Colombo C (2005). Soil enzyme activities as affected by anthropogenic alterations: Intensive agricultural practices and organic pollution. Science of the Total Environment, 341, 265-279.

Giese M, Brueck H, Gao YZ, Lin S, Steffens M, Kögel-Knabner I, Glindemann T, Susenbeth A, Taube F, Butterbach-Bahl K, Zheng XH, Hoffmann C, Bai YF, Han XG (2013). N balance and cycling of Inner Mongolia typical steppe: A comprehensive case study of grazing effects. Ecological Monographs, 83, 195-219.

Guan SY (1986). Soil Enzymes and Its Research Methods. Agriculture Press, Beijing. 62-64. [关松荫 (1986). 土壤酶 及其研究法. 农业出版社, 北京. 62-64.]

Guo J, Mcculley RL, Phillips TD, Mcnear DH (2016). Fungal endophyte and tall fescue cultivar interact to differentially affect bulk and rhizosphere soil processes governing $\mathrm{C}$ and N cycling. Soil Biology \& Biochemistry, 101, 165-174.

Hamer U, Marschner B (2005). Priming effects in soils after combined and repeated substrate additions. Geoderma, $128,38-51$.

Hu JJ, Chen SL, Guo ZW, Yang QP, Li YC (2015). Effects of spacer length on water physiological integration of Indocalamus decorus ramets under heterogeneous water supply. Acta Botanica Boreali-Occidentalia Sinica, 35, 2532-2541. [胡俊靖, 陈双林, 郭子武, 杨清平, 李迎春 (2015). 间隔子长度对美丽箬竹克隆分株水分生理整合 效应的影响. 西北植物学报, 35, 2532-2541.]

Jones DL, Nguyen C, Finlay RD (2009). Carbon flow in the rhizosphere: Carbon trading at the soil-root interface. 
Plant and Soil, 321, 5-33.

Jónsdóttir IS, Callaghan TV (1990). Intraclonal translocation of ammonium and nitrate nitrogen in Carex bigelowii Torr. ex Schwein. using ${ }^{15} \mathrm{~N}$ and nitrate reductase assays. New Phytologist, 114, 419-428.

Kandeler E, Gerber H (1988). Short-term assay of soil Urease activity using colorimetric determination of ammonium. Biology \& Fertility of Soils, 6, 68-72.

Koranda M, Schnecker J, Kaiser C, Fuchslueger L, Kitzler B, Stange CF, Sessitsch A, Zechmeister-Boltenstem S, Richter A (2011). Microbial processes and community composition in the rhizosphere of European beech-The influence of plant C exudates. Soil Biology \& Biochemistry, 43, $551-558$.

Kuzyakov Y (2002). Factors affecting rhizosphere priming effects. Journal of Plant Nutrition \& Soil Science, 165, 382-396.

Kuzyakov Y, Bol R (2006). Sources and mechanisms of priming effect induced in two grassland soils amended with slurry and sugar. Soil Biology \& Biochemistry, 38, 747-758.

Kuzyakov Y, Hill PW, Jones DL (2007). Root exudate components change litter decomposition in a simulated rhizosphere depending on temperature. Plant and Soil, 290, 293-305.

Lei NF, Li J, Ni SJ, Chen JS (2014). Effects of clonal integration on microbial community composition and processes in the rhizosphere of the stoloniferous herb Glechoma longituba (Nakai) Kuprian. PLOS ONE, 9, e108259. DOI: 10.1371/journal.pone.0108259.

Li LH (2016). Preliminary Study in the Mechanism of the Effect of Long Term Fertilization on the Growth of Wheat Seeding. $\mathrm{PhD}$ dissertation, Chinese Academy of Agricultural Sciences, Beijing. 71. [李丽华 (2016). 长期定位施肥红 壤影响小麦苗期生长的微生物机制初探. 博士学位论 文, 中国农业科学院, 北京. 71]

Li MH, Hoch G, Körner C (2002). Source/sink removal affects mobile carbohydrates in Pinus cembra at the Swiss treeline. Trees, 16, 331-337.

Li R, Zhang J, Zhang ZE (2003). Values of bamboo biodiversity and its protection in China. Journal of Bamboo Research, 22(4), 7-12. [李睿, 章笕, 章珠娥 (2003). 中国 竹类植物生物多样性的价值及保护进展. 竹子研究汇 刊, 22(4), 7-12.]

Li YP, Liu GS, Ding SH, Li JJ, Yan HT, Yan S (2016). Effects of mixed organic fertilizer amount on root vigor and rhizosphere soil biological characteristics of flue-cured tobacco. Chinese Tobacco Science, 37(1), 32-36. [李艳平, 刘国顺, 丁松爽, 李静静, 阎海涛, 阎申 (2016). 混合 有机肥用量对烤烟根系活力及根际土壤生物特性的影 响. 中国烟草科学, 37(1), 32-36.]

Liu J, Yang QP, Song QN, Yu DK, Yang GY, Qi HY, Shi JM (2013). Strategy of fine root expansion of Phyllostachys pubescens population into evergreen broadleaved forest.
Chinese Journal of Plant Ecology, 37, 230-238. [刘骏, 杨 清培, 宋庆妮, 余定坤, 杨光耀, 祁红艳, 施建敏 (2013). 毛竹种群向常绿阔叶林扩张的细根策略. 植物 生态学报, 37, 230-238.]

Marshall C (1990). Source-sink relations of interconnected ramets. In: van Groenendael, de Kroon eds. Clonal Growth in Plants: Regulation \& Function. SPB Academic Publishing, The Hague. 23-41.

Mcmurtrie RE, Medlyn BE, Dewar RC (2001). Increased understanding of nutrient immobilization in soil organic matter is critical for predicting the carbon sink strength of forest ecosystems over the next 100 years. Tree Physiology, 21, 831-839.

Parham JA, Deng SP (2000). Detection, quantification and characterization of beta-glucosaminidase activity in soil. Soil Biology \& Biochemistry, 32, 1183-1190.

Paul EA, Clark FE (1989). Preface-soil microbiology and biochemistry. Soil Microbiology \& Biochemistry, 51, 6-7.

Peng YK, Luo FL, Li HL, Yu FH (2013). Growth responses of a rhizomatous herb Bolboschoenus planiculmis to scale and contrast of soil nutrient heterogeneity. Chinese Journal of Plant Ecology, 37, 335-343. [彭一可, 罗芳丽, 李 红丽, 于飞海 (2013). 根状茎型植物扁秆荆三棱对土壤 养分异质性尺度和对比度的生长响应. 植物生态学报, 37, 335-343.]

Perucci P, Casucci C, Dumontet S (2000). An improved method to evaluate the o-diphenol oxidase activity of soil. Soil Biology \& Biochemistry, 32, 1927-1933.

Ping XY, Zhou GS, Sun JS (2010). Advances in the study of photosynthate allocation and its controls. Chinese Journal of Plant Ecology, 34, 100-111. [平晓燕, 周广胜, 孙敬松 (2010). 植物光合产物分配及其影响因子研究进展. 植 物生态学报, 34, 100-111.]

Pitelka LF, Ashmun JW (1985). Physiology and integration of ramets in clonal plants. In: Jackson JBC, Buss LW, Cook RE eds. Population Biology \& Evolution of Clonal Organisms. Yale University Press, New Haven. 399-437.

Price EAC, Hutchings MJ (1992). The causes and developmental effects of integration and independence between different parts of Glechoma hederacea clones. Oikos, 63, 376-386.

Qin SW, Liu ZY (1984). The nutrient status of soil-root interface III. Variation of fertilizer nitrogen in rice rhizosphere. Acta Pedologica Sinica, 21, 238-246. [钦绳武, 刘芷宇 (1984). 土壤一根系微区养分状况的研究—-III. 水 稻根际氮素的变化. 土壤学报, 21, 238-246.]

Qiu EF, Hong W, Zheng YS (2001). Review on diversity and utilization of bamboo in China. Journal of Bamboo Research, 20(2), 11-14. [邱尔发, 洪伟, 郑郁善 (2001). 中 国竹子多样性及其利用评述. 竹子研究汇刊, 20(2), 11-14.]

Rajaniemi TK, Allison VJ (2009). Abiotic conditions and plant

www.plant-ecology.com 
cover differentially affect microbial biomass and community composition on dune gradients. Soil Biology \& Biochemistry, 41, 102-109.

Riley D, Barber SA (1970). Salt accumulation at the soybean (Glycine max (L.) Merr) root-soil interface. Soil Science Society of America Journal, 34, 154-155.

Schimel JP, Bennett J (2004). Nitrogen mineralization: Challenges of a changing paradigm. Ecology, 85, 591-602.

Schimel JP, Weintraub MN (2003). The implications of exoenzyme activity on microbial carbon and nitrogen limitation in soil: A theoretical model. Soil Biology \& Biochemistry, 35, 549-563.

Setia R, Verma SL, Marschner P (2012). Measuring microbial biomass carbon by direct extraction-Comparison with chloroform fumigation-extraction. European Journal of Soil Biology, 53, 103-106.

Shi JM, Ye XH, Chen FS, Yang QP, Li ZY, Fang K, Yang GY (2014). Adaptation of bamboo to heterogeneous habitat: Phenotypic plasticity. Acta Ecologica Sinica, 34, 5687-5695. [施建敏, 叶学华, 陈伏生, 杨清培, 黎祖尧, 方楷, 杨光耀 (2014). 竹类植物对异质生境的适应表型可塑性. 生态学报, 34, 5687-5695.]

Smucker RA, Kim CK (1987). Chitinase induction in an estuarine system. In: Llewellyn GC, O'Rear CE eds. Biodeterioration Research. Plenum Press, New York. 347-355.

Song HX, Jiang MY, Chen QB (2011). Point pattern analysis of Phyllostachys bissetii ramet population in West China Rainy Area. Chinese Journal of Applied Ecology, 22, 1135-1140. [宋会兴, 江明艳, 陈其兵 (2011). 华西雨 屏区白夹竹分株种群的点格局分析. 应用生态学报, 22, 1135-1140.]

Stuefer JF (1996). Potential and limitations of current concepts regarding the response of clonal plants to environmental heterogeneity. Vegetatio, 127, 55-70.

Sun Y, Xu XL, Kuzyakov Y (2014). Mechanisms of rhizosphere priming effects and their ecological significance. Chinese Journal of Plant Ecology, 38, 62-75. [孙 悦, 徐兴良, Kuzyakov Y (2014). 根际激发效应的发生 机制及其生态重要性. 植物生态学报, 38, 62-75.]

Toberman H, Chen C, Xu Z (2011). Rhizosphere effects on soil nutrient dynamics and microbial activity in an Australian tropical lowland rainforest. Soil Research, 49, 652-660.

Trudell SA, Rygiewicz PT, Edmonds RL (2004). Patterns of nitrogen and carbon stable isotope ratios in macrofungi, plants and soils in two old-growth conifer forests. New Phytologist, 164, 317-335.

Vance E, Brooks P, Jenkinson D (1987). An extraction method for measuring soil microbial biomass. Soil Biology \& Biochemistry, 19, 703-707.

Wang CA, Li DZ, Zhu ZL, Wang XP, Sheng LJ, Shi Q (2006). Research methods for physiological integration of clonal plants and their application. Chinese Journal of Applied \&
Environmental Biology, 12, 581-588. [王长爱, 李德志, 朱志玲, 王绪平, 盛丽娟, 石强 (2006). 克隆植物生理 整合作用的研究方法及其应用. 应用与环境生物学报, 12, 581-588.]

Wang YS, Hong RM, Huang DM, Teng XH, Li YS, Masae S, Miki N (2004). The translocation of photosynthate between clonal ramets of Leymus chinensis population. Acta Ecologica Sinica, 24，900-907. [王昱生，洪锐民，黄大 明, 滕小华, 李月树, 盐见正卫, 中村未树 (2004). 羊 草种群克隆分株之间光合产物的转移. 生态学报, 24 , 900-907.]

Wei YH, Zhou XB, Chen JS, Chen LM, Li J, Liu Q (2013). Effect of clonal integration on ramet population regeneration of two Fargesia (bamboo) species under simulated ingesting interference. Chinese Journal of Plant Ecology, 37, 699-708. [魏宇航, 周晓波, 陈劲松, 谌利民, 李娇, 刘庆 (2013). 模拟采食干扰下克隆整合对两种箭竹分 株种群更新的影响. 植物生态学报, 37, 699-708.]

Witt C, Gaunt JL, Galicia CC, Ottow JCG, Neue HU (2000). A rapid chloroform-fumigation extraction method for measuring soil microbial biomass carbon and nitrogen in flooded rice soils. Biology \& Fertility of Soils, 30, 510-519.

Wu J, Joergensen RG, Pommerening B, Chaussod R, Brookes PC (1990). Measurement of soil microbial biomass C by fumigation-extraction-An automated procedure. Soil Biology \& Biochemistry, 22, 1167-1169.

Wu X, Wu FZ, Zhou XG (2015). Effect of intercropping with tillered onion on mineral nutrient uptake and gray modal disease occurrence of tomato. Journal of Plant Nutrition \& Fertilizer，21，734-742. [吴瑕，吴凤芝，周新刚 (2015). 分臬洋葱伴生对番茄矿质养分吸收及灰霉病发生的影 响. 植物营养与肥料学报, 21, 734-742.]

Xue G, Li Y, Chen JS, Song HX (2018). Effect of clonal integration on soil microbial properties in the rhizosphere of Phyllostachys bissetii, subjected to heterogeneous light. Acta Ecologica Sinica, 38, 3132-3144. [薛阁, 李洋, 陈 劲松, 宋会兴 (2018). 克隆整合对遮阴白夹竹分株根际 土壤细菌生物特征的影响. 生态学报, 38, 3132-3144.]

Yang QP, Guo YR, Lan WJ, Song QN, Yang GY (2017). Addition effects of co-expansion of two bamboos on plant diversity in broad-leaved forests. Chinese Journal of Applied Ecology, 28，3155-3162. [杨清培, 郭英荣, 兰文军, 宋庆 妮, 杨光耀 (2017). 竹子扩张对阔叶林物种多样性的影 响: 两竹种的叠加效应. 应用生态学报, 28, 3155-3162.]

Zaman M, Chang SX (2004). Substrate type, temperature, and moisture content affect gross and net $\mathrm{N}$ mineralization and nitrification rates in agroforestry systems. Biology \& Fertility of Soils, 39, 269-279.

Zeng AP, Wang YY, Xu XW, Liu HJ, Chen ZL (2007). Study on Dendrocalamopsis oldhami promoting cultivation technique. Journal of Zhejiang Agricultural Sciences, 1, 
509-511. [曾爱平, 王月英, 徐晓薇, 刘洪见, 陈中林 (2007). 马蹄笋促成栽培技术研究. 浙江农业科学, 1, 509-511.]

Zeng L, Ren P, Li ZX, Yang DS, Mu XW, Chen ZY, Chen DC (1998). Report of biological features of Phyllostachys nidularia. Economic Forest Researches, 16(4), 9-11. [曾 林, 任凭, 李中祥, 杨大胜, 牟晓伟, 陈正與, 陈代昌 (1998). 白夹竹生物学特性观察. 经济林研究, 16(4), 9-11.]

Zhang CY, Yang C, Dong M (2001). The clonal integration of photosynthates in the rhizomatous half-shrub Hedysarum laeva. Acta Ecologica Sinica, 21, 1986-1993. [张称意, 杨 持, 董鸣 (2001). 根茎半灌木羊柴对光合同化物的克隆 整合. 生态学报, 21, 1986-1993.]

Zhang JE, Liu WG, Chen JQ, Shi YC, Cai YF (2005). Effects of different cutting intensities of Stylosanthes guianensis (Aubl.) SW. on soil nutrients and soil enzyme activities in rhizosphere. Ecology \& Environment, 14, 387-391. [章家 恩, 刘文高, 陈景青, 施耀才, 蔡燕飞 (2005). 刏割对 牧草地下部根区土壤养分及土壤酶活性的影响. 生态 环境, 14, 387-391.]

Zhang Q (2016). Root Exuduation and Effect of Root Exduate to Soil Nitrogen Transformation in Poplar and Alder Mixed Plantation. Master degree dissertation, Nanjing Forest University, Nanjing. 65. [章晴 (2016). 杨一桤混 交林根系碳分泌及其对根际土壤氮转化的影响. 硕士 学位论文, 南京林业大学, 南京. 65.]

Zhang WJ (2014). Response of Leymus Chinensis Clonal Integration to Heterogeneous Alkaline Environment. $\mathrm{PhD}$ dis- sertation, China Agricultural University, Beijing. 2-14. [张文军 (2014). 羊草克隆整合对碱环境异质性的响应. 博士学位论文, 中国农业大学, 北京. 2-14.]

Zhang Y, Chen JS (2017). Effects of clonal integration on the nitrogen availability of rhizosphere soil in Phyllostachys nigra suffering from heterogeneous light. Guihaia, 37, 757-762. [张云, 陈劲松 (2017). 克隆整合对异质性光 照环境下紫竹根际土壤氮素有效性的影响.广西植物, 37, 757-762.]

Zhao JS, Zhang XD, Yuan X, Wang J (2003). Characteristics and environmental significance of soil dissolved organic matter. Chinese Journal of Applied Ecology, 14, 126-130. [赵劲松, 张旭东, 袁星, 王晶 (2003). 土壤溶解性有机 质的特性与环境意义. 应用生态学报, 14, 126-130.]

Zhou SQ, Huang JY, Zhang YH, Li RG, Li DS, Zhang HM (2009). The effects of wildness training giant pandas grazing and artificial harvesting on the regeneration of umbrella bamboo (Fargesia robusta) clone population. Acta Ecologica Sinica, 29, 4804-4814. [周世强, 黄金燕, 张亚辉, 李仁贵, 李德生, 张和民 (2009). 野化培训大 熊猫采食和人为砍伐对拐棍竹无性系种群更新的影响. 生态学报, 29, 4804-4814.]

Zhou WM, Chen H, Zhou L, Lewis BJ, Ye YJ, Tian J, Li GW, Dai LM (2011). Effect of freezing-thawing on nitrogen mineralization in vegetation soils of four landscape zones of Changbai Mountain. Annals of Forest Science, 68, 943-951.

责任编委: 于飞海 责任编辑: 李 敏 